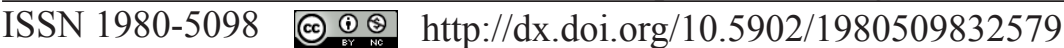

\title{
IMPORTÂNCIA DO MANEJO DE FLORESTAS NATIVAS PARA A RENDA DA PROPRIEDADE E ABASTECIMENTO DO MERCADO MADEIREIRO
}

\section{IMPORTANCE OF NATIVE FOREST MANAGEMENT FOR INCOME OF FARMS AND THE SUPPLY OF TIMBER MARKETS}

\author{
Franz Heinrich Andrae ${ }^{1}$ Paulo Renato Schneider ${ }^{2}$ Miguel Antão Durlo ${ }^{2}$
}

\begin{abstract}
RESUMO
A produção brasileira de madeira industrial baseia-se essencialmente nas plantações florestais, porém, somente no setor de serraria existe ainda uma parcela apreciável de toras de origem de florestas nativas, desconsiderando o uso da madeira para fins energéticos. Com a criação de concessões florestais deu-se um passo importante rumo ao manejo das florestas nativas do norte do país. Já no extremo sul existem florestas nativas somente em estágios de recuperação, em propriedades familiares e cujo manejo é muito restrito. No presente artigo argumenta-se sobre a importância de manejar as florestas nativas, mesmo em pequenas propriedades. Para isto, toma-se como exemplo o caso da Áustria, cujo território é dominado por florestas nativas em pequenas propriedades. A tradição deste uso é baseada em uma legislação adequada, no trabalho do serviço de extensão e de pesquisa que geram um ambiente no qual os benefícios materiais e imateriais da floresta se aliam aos interesses da sociedade e aos econômicos dos proprietários. O manejo das pequenas unidades florestais permite alcançar um regime de sustentabilidade periódico, cujas intervenções silviculturais partem das condições locais, sendo o objetivo central a árvore e não o povoamento. Este procedimento de manejo, atualmente recomendado para a produção de madeira de elevado valor econômico, é descrito de maneira resumida.
\end{abstract}

Palavras-chave: floresta colonial; floresta mista; latifoliadas.

\begin{abstract}
The Brazilian production of industrial timber depends mainly on forest plantations; only in the sawmill sector, there is still the use of a considerable amount of logs originating from natural forests. Recently forest concessions were created; this was an important step toward the management of native forests in the North. In the very South of Brazil, native forests exist mainly in stages of regeneration, belonging to small-scale farmers with restricted opportunities for management. The present article argues the importance of native forest management even when they belong to small landowners. An example from Austria is given where small ownership is dominating native forests. There is a framework of traditional use, an

1 Engenheiro Florestal, Dr., Professor do Department of Forest and Soil Sciences, Institute of Forest Growth, University of Natural Resources and Applied Life Sciences, Vienna. Peter-Jordan-Str. 82, A-1190 Vienna, Áustria. franz.andrae@boku.ac.at

2 Engenheio Florestal, Dr., Professor do Departamento de Ciências Florestais, Centro de Ciências Rurais, Universidade Federal de Santa Maria, Av. Roraima, 1000, CEP 97105900, Santa Maria (RS), Brasil. schneider.paulorenato@gmail. com / migueldurlo@gmail.com
\end{abstract}

Recebido para publicação em 7/07/2011 e aceito em 11/01/2017

Ci. Fl., v. 28, n. 3, jul. - set., 2018 
adequate legislation and the effort of extension service, able to ally immaterial social benefits and economic interest of forest owners. The management of generally small forest units is aiming a so-called periodic sustainability; decisions of silvicultural treatments are based on local conditions, where to an individual tree is given more attention than to the stand; the objective of management is mainly timber of high value; a summarized description of practical procedure is given.

Keywords: family forestry; mixed forests; broadleaved species.

\section{INTRODUÇÃO}

O Brasil, país com a maior área de florestas naturais tropicais do mundo, ciente da riqueza que possui, protege-as com uma legislação ambiental bastante rígida. A administração florestal desenvolveu modelos interessantes, como as já tradicionais reservas extrativistas e o direito da exploração de florestas públicas por meio de concessões florestais. Os dois modelos, na prática, são direcionados à região norte

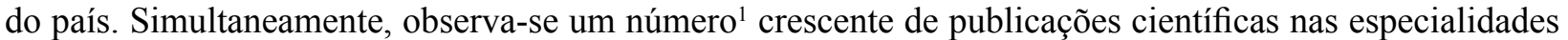
de biometria, silvicultura e de economia florestal (INSTITUTO DO HOMEM E MEIO AMBIENTE DA AMAZÔNIA, 2008).

No Rio Grande do Sul, a devastação ocorrida durante o processo de ocupação territorial, a mudança no uso da terra e a evolução da legislação que regula o uso da floresta tornou-se rígida e muito pouco flexível, por vezes, inexequível. Neste contexto, faltam mecanismos menos agressivos que possibilitem o uso racional das florestas naturais.

Este trabalho busca contribuir para a discussão a respeito do uso deste tipo florestal e não tem o intuito de provocar ou mexer em tabus, mas, sim, convidar as pessoas à reflexão sobre uma potencialidade florestal, real e presente, praticamente ociosa no estado.

O manejo não é apenas a aplicação de uma técnica, pois a própria Secretaria do Meio Ambiente do Rio Grande do Sul (RIO GRANDE DO SUL, 2008) o define em sentido mais amplo, como sendo a utilização de ecossistemas para que as comunidades possam desfrutar dos produtos biológicos, subentendendo-se que deveriam fazer parte desta comunidade beneficiada os proprietários de bens de interesse comum.

Existem opiniões divergentes sobre o manejo de florestas nativas, e sobre o futuro de sua utilização, já que o progresso com as plantações florestais poderia atender à demanda de madeira, sobrando, para as florestas naturais, a produção de bens imateriais (TOMASELLI, 2001), o que não está muito distante da realidade do Rio Grande do Sul, porém, a capacidade é outra. Para exemplificar, na América Central, a análise econômica revelou a dificuldade que a floresta natural (sem manejo) enfrenta ao competir com plantações florestais ou com a pecuária (NIEUWENHUYSE et al., 2000). É óbvio que tal análise econômica baseava-se nos preços vigentes à época naquela região e, portanto, os resultados foram válidos somente para as alternativas testadas. Por outro lado, são menos citados e considerados os casos em que o manejo de florestas nativas, em pequenas propriedades, pode contribuir substancialmente para a economia nacional e para a manutenção da qualidade ambiental, como no exemplo apresentado a seguir.

\section{PONTO DE PARTIDA}

Com relação às florestas nativas deve-se pensar no seu ambiente socioeconômico e histórico tão diferente das outras regiões do território nacional. É singular a coincidência entre a propriedade familiar e a região da ocorrência natural das florestas no Rio Grande do Sul, onde ocorre, há quase dois séculos, o processo de substituição das florestas pelo uso agropecuário.

Por outro lado, o processo de retorno das florestas em decorrência do abandono da pequena propriedade ocorre, certamente, em um ritmo mais rápido do que era o próprio desmatamento. Os dados obtidos pelos inventários florestais do estado do Rio Grande do Sul comprovam estas afirmativas.

A modificação da paisagem do Rio Grande do Sul é significativa, pois tem se tornado mais florestada (IBAMA, 2010), mas mais abandonada e decadente nas suas estruturas. Isto não se deve a uma decisão consciente de optar pela floresta, mas sim da falta de alternativas de produção na pequena propriedade 
em situação topográfica e edáfica difícil, em áreas de vocação florestal. As limitações naturais de muitas regiões coloniais impõem para o agricultor sobreviver com a produção agrícola, sem poder manejar florestas naturais como uma alternativa econômica, que poderia contribuir para frear o êxodo rural. Certamente, a estrutura fundiária na região de florestas nativas dificulta o manejo das florestas; porém, a produção de madeira deveria ser considerada como um produto igual a outros, permitindo uma renda adicional, objetivo procurado há anos. Neste sentido, a acacicultura no Rio Grande do Sul, praticada no minifúndio, prova que os agricultores são capazes de operar eficientemente com cultivo florestal. Entretanto, a atividade com as florestas nativas, logicamente, é uma tarefa exigente e justamente por isso, mais urgente de ser iniciada.

\section{COMO SE APRESENTA O CONSUMO}

O discurso público atual deixa transparecer que a causa florestal no Rio Grande do Sul está centralizada na geração de matéria-prima para a indústria de celulose. Sem dúvida, um segmento importantíssimo, porém, não o único.

$\mathrm{O}$ consumo de lenha para uso caseiro e industrial supera em muito o destinado à indústria de celulose, existindo ainda um consumo de madeira, normalmente importada de estados do norte, que poderia ser produzida pelas florestas nativas locais. Duas referências comprovam esses dados. A primeira, com dados de 1997, Smeraldi e Veríssimo (1999) quantificaram 1,2 milhões de metros cúbicos de madeira serrada trazida da Amazônia, ou seja, 42 \% da madeira serrada da Amazônia é consumida no sul e sudeste do Brasil.

O transporte destas quantidades, que em muitos casos provêm de cortes ilegais, é realizado por rodovia (SOCIEDADE BRASILEIRA DE SILVICULTURA, 2006). Pode-se considerar nisto várias deficiências ecológicas, que bem justificam a produção de quantidades comparáveis no sul do Brasil, beneficiando a economia local e diminuindo a "pegada ecológica" deste material de consumo.

Neste sentido, desde 2008, as três maiores cidades do Rio Grande do Sul e mais um Banco exigem que a madeira proveniente do norte do país tenha origem comprovadamente legal. Talvez, a próxima decisão ecologicamente correta seria passar a substituir a madeira proveniente do norte pela produzida no sul do país.

\section{O MANEJO DA FLORESTA NATURAL E O CONCEITO DE SUSTENTABILIDADE REQUEREM O DISCURSO CIENTÍFICO}

A sustentabilidade não é sinônimo único de proteção da natureza, mas principalmente de produção, visto que a primeira não pode existir sem a segunda. Assim, o uso sustentável pode ser a maior garantia da continuidade de um sistema, ao contrário de uma exclusiva proteção da natureza. Utilizar de forma racional é, também, a garantia da manutenção da dimensão econômica para o desenvolvimento sustentável como foi postulado pela Conferência do Rio 92.

No Rio Grande do Sul são quase cinco milhões de hectares de florestas naturais, incluindo todos os estágios de sucessão, conforme comprovado no inventário florestal realizado em 2000.

O acompanhamento técnico deste processo, visando a um futuro aproveitamento, poderia abrir uma nova perspectiva econômica para as áreas florestais.

O maior obstáculo não é o conhecimento da técnica de manejo, mas a superação de entraves administrativos e de paradigmas. Também, é verdade que o manejo sustentável somente será econômico enquanto não houver competição por produtos de origem de exploração extrativista.

Sem dúvida, existe interesse na utilização da floresta natural, mas também não há dúvida que, no Rio Grande do Sul, parece ser uma profanação pensar em silvicultura, arte para qual a Engenharia Florestal possui as ferramentas de execução. Para exemplificar, pode-se analisar a relação dos 71 trabalhos 
voluntários do Simpósio Latino-Americano sobre Manejo Florestal realizado em 2008, em Santa MariaRS. Destes, trinta e oito tratavam de florestas nativas, vinte e cinco de florestas nativas do Rio Grande do Sul, mas de forma descritiva e, somente cinco trabalhos podem ser relacionados com a biometria ou o manejo. Por isto, é preciso desenvolver mais pesquisas sobre a autoecologia e comportamento vegetativo das espécies e suas interações com o ambiente local, tornando mais seguro o manejo. O manejo destes tipos florestais não necessariamente precisa de fórmulas e planos sofisticados, mas a simples transferência de algumas regras básicas para a prática, pois no manejo é válido desenvolver receitas simples para aplicá-las às realidades complexas.

As informações obtidas nos inventários florestais de grande escala, por outro lado, deveriam servir como justificativas para a adoção de políticas públicas e para a elaboração da legislação florestal. A nosso ver, o Rio Grande do Sul precisa tomar um novo rumo e ter uma visão diferente sobre o conceito de funcionalidade de florestas.

\section{PERSPECTIVAS DIFERENTES NAS FUNÇÕES FLORESTAIS}

Comparando os paradigmas do Rio Grande do Sul com os de países do centro-europeu, como a Áustria, percebe-se uma interpretação completamente diferente dos conceitos de uso múltiplo das florestas e da exigência de manutenção das funções florestais.

No Rio Grande do Sul, entende-se como uso múltiplo a possibilidade de obter vários sortimentos ao explorar um povoamento, já que, nos tempos dos incentivos fiscais, os plantios foram feitos com finalidade única, seja carvão, celulose, chapas ou tábuas; pois ao diversificar o emprego da madeira colhida obtém-se maior valorização da floresta e de sua produção. Já as funções não produtivas foram definidas, como sendo um atributo das florestas nativas, portanto, conduzindo a uma separação espacial de áreas cobertas por árvores, umas com rendimento e outras sem.

No conceito austríaco, o uso múltiplo não se aplica à produção de matéria-prima, mas às funções florestais, devendo cada área florestada, cumprir quatro funções simultaneamente: produção, proteção, benefícios ecológicos e lazer. Com isto é óbvio que cada parcela florestal pode ser manejada, desde que sejam cumpridas suas funções sociais. Assim, ficam garantidos à sociedade os benefícios imateriais, sem privar os proprietários dos benefícios econômicos. Este fato é uma das razões pelas quais nunca se hesita em manejar tudo o que a lei define como floresta e, neste caso, as florestas nativas, pois se desconhecem grandes cultivos com espécies exóticas. Deve-se salientar que na Áustria existem somente 50 espécies arbóreas, e que em muitas regiões o clima limita a diversidade natural, sendo que a lei, a ciência florestal e a prática do manejo orientam-se sob estas condições.

Outra particularidade é a dominância da floresta colonial, florestas em minifúndios, sendo que inexistem florestas pertencentes a grandes indústrias de transformação.

A experiência mostra que, conforme a localização geográfica e topográfica, a dominância de uma ou outra função varia, pois o país é montanhoso e com densidade demográfica elevada. Entretanto, é consenso geral conceder ao proprietário o direito de manejar qualquer floresta, sempre com a responsabilidade de seguir as normas de uma legislação florestal rígida, que é fiscalizada, mesmo nas localidades mais afastadas.

A política florestal, não somente da Áustria, como de toda a União Europeia, contempla de forma clara a importância das florestas para atender aos interesses ecológicos, sociais, culturais e espirituais e dá a mesma atenção a todas as funções florestais, garantindo o uso do potencial produtivo em benefício da manutenção da estrutura agrária do interior (GLÜCK, 1999).

\section{FLORESTA NATIVA E A PEQUENA PROPRIEDADE}

Aproximadamente, a metade do território nacional da Áustria é coberto de florestas, correspondendo a cerca de 4 milhões de hectares, dos quais 15 \% são considerados improdutivos. Da área restante, ou seja, das florestas produtivas, $56 \%$ pertencem a pequenos proprietários, $31 \%$ a empresas e $13 \%$ a Florestas Nacionais.

O efeito da estrutura fundiária, dominada pela pequena e média propriedade, com florestas nativas manejadas sob o conceito de uso múltiplo, pode parecer complexa para a administração pública e privada. 
Contudo, mesmo com essas características, o país ocupa um lugar de destaque no mercado de madeira, sendo, por exemplo, o quarto maior exportador de madeira serrada do mundo. Segundo o Ministério de Agricultura e Florestas (LEBENSMINISTERIUM, 2008), foram produzidos na Áustria, em 2007, cerca de 11,3 milhões de metros cúbicos de madeira serrada, 1 milhão de metros cúbicos a mais que toda a Amazônia, no mesmo período (LENTINI; VERISSIMO; PEREIRA, 2005).

A lei florestal da Áustria é a mesma para todos os tipos de florestas, o que possibilita serem utilizadas e manejadas livremente, desde que se garanta a manutenção de suas funções sociais. Mesmo os poucos povoamentos com espécies exóticas estão sujeitos aos mesmos critérios legais e padrões das certificadoras.

Como instrumento da política florestal, o inventário florestal sistemático é executado sobre 11.000 parcelas amostrais permanentes, cujo resultado serve para, entre outros, atualizar os enfoques de fiscalização, apoio, incentivo aos produtores, etc.

$\mathrm{Na}$ Áustria, existem cerca de 210.000 proprietários florestais que são apoiados nos seus trabalhos pelo sistema escolar profissionalizante, além da atividade de técnicos de vários níveis, e por cerca de 1.000 Engenheiros Florestais.

Para garantir o manejo e a manutenção dos ecossistemas, a lei obriga que em propriedades maiores seja contratado um ou mais técnicos ou Engenheiro Florestal. Já os proprietários com áreas pequenas são assistidos por centros regionais de aperfeiçoamento agrícola, cujos currículos oferecem maior ou menor ênfase a matérias relacionadas ao manejo florestal. Para estes proprietários, sobretudo, está à disposição o Serviço de Extensão Florestal com técnicos e Engenheiros Florestais. O próprio Serviço Florestal (correspondente à Secretaria da Agricultura/RS) considera a sua função, não somente a de fiscalizar o cumprimento da legislação florestal, mas principalmente como de indutor de serviços de assistência e de perícia técnica.

Esta estrutura fundiária e a assistência técnica do setor público representam, por um lado, a parte da produção florestal confrontada nos processos de concentração de mercado, bem como os paradigmas ambientais da sociedade. O aumento da capacidade das indústrias de transformação, como as serrarias e as indústrias de celulose, por exemplo, levou à maior procura de matéria-prima, para a qual não existe a mesma capacidade de abastecimento imediato, já que a produção florestal encontra os limites impostos pela sustentabilidade. Este processo, obviamente, conduziu a um desequilíbrio entre parceiros de mercado, dificultando a posição dos proprietários florestais, sobretudo dos pequenos, com quantidades modestas de venda anual.

Desta forma tornou-se indispensável, para o setor, organizar-se para incrementar seu peso no mercado. Para atender a essa necessidade, o Serviço de Extensão iniciou, há pouco mais de 10 anos, um programa de fomento à criação de "Comunidades de Manejo Florestal" (CMF), organizações voluntárias locais, com funcionamento semelhante a cooperativas.

Entre as finalidades das CMF estão a ajuda mútua no manejo, a organização da comercialização conjunta, a aquisição comunitária de máquinas, acessórios e materiais de consumo. Simultaneamente, o Serviço de Extensão organiza a venda pública de toras de qualidade, muitas vezes de espécies menos frequentes e raras. Esta iniciativa foi muito bem aceita, pois o agricultor tem a oportunidade de obter preços excepcionais, mesmo ofertando, tão somente, uma ou duas árvores.

Este evento anual de comercialização fez crescer muito o interesse dos agricultores em realizar tratamentos de melhoria qualitativa das árvores e das florestas, assim como favorecer o crescimento de espécies um tanto raras.

Em relação aos paradigmas ambientais, verificou-se nas últimas décadas um sucessivo distanciamento da população urbana da realidade rural, e o aumento das pressões sobre o setor de produção, confrontando o produtor rural com exigências ambientais ingratas.

Como forma de esclarecimento e de proteção o Serviço de Extensão Florestal apoia amplos programas de educação ambiental na busca da reconciliação entre ecologia e economia.

Paralelamente à indústria de turismo ecológico convenceu-se que é justo integrar os proprietários florestais no seu planejamento, bem como estabelecer indenizações para algumas exigências ambientais, induzindo a sociedade a valorizar seus interesses imateriais na floresta. 


\section{O MANEJO DA FLORESTA NATIVA NA PEQUENA PROPRIEDADE}

Anteriormente, mostrou-se que existem estruturas e iniciativas administrativas na Áustria que apoiam o setor de produção. Mas o que interessa ainda mais é a maneira como se lida tecnicamente com a combinação de floresta natural em pequenas propriedades.

No Sul do Brasil sente-se, naturalmente, a existência de certo mal-estar ao se buscar a intervenção em qualquer floresta nativa. Talvez isto seja uma consequência da diversidade e da dialética imponente sobre a definição dos objetivos e sobre o significado de sustentabilidade, neste sistema florestal natural.

A revista Ciência Florestal, editada pela Universidade Federal de Santa Maria está repleta de publicações que abordam a fitossociologia de ecossistemas florestais nativos que se encontram em processo permanente de transformação de suas estruturas e da composição florística, portanto, de comunidades dinâmicas. No entanto, entende-se que a pesquisa deveria avançar, pois sustentabilidade significa estabilidade e continuidade. A continuidade exigida reside sobre a função extraeconômica, e ocorre independentemente do estágio atual de sucessão. Com isto, justificam-se intervenções e aproveitamentos, sem pôr em dúvida os benefícios imateriais desejados da floresta nativa.

Para manejar as florestas na Áustria não é obrigatório possuir um "plano de manejo", mesmo assim, é evidente que cada empresa florestal o possua, pois é de seu próprio interesse organizar sua produção madeireira.

O plano é baseado no inventário florestal e outros levantamentos, sendo renovado a cada 10 anos. As propriedades maiores podem executar o chamado regime sustentado anual, sob a aplicação das teorias de manejo existentes: organizar os povoamentos equiâneos ou inequiâneos, e ajustar as intervenções previstas aos objetivos definidos de sustentabilidade, incluindo a determinação da taxa de corte anual para a década seguinte.

Esse processo é um tanto diferente quando se trata de propriedades rurais com áreas florestais menores, de poucos hectares, e com florestas mistas em espécies e idades, possivelmente sem estruturação. Nestas propriedades, a floresta gera somente uma parte da renda, e os cortes, geralmente, seguem um regime periódico, principalmente, quando o agricultor considera sua floresta como uma caderneta de poupança. Neste caso, não se justifica a elaboração de planos de manejo sofisticados, nem é possível organizar estruturas físicas regulares em classes de idade.

Para qualquer tipo de propriedade, a lei é bastante liberal quanto às atividades econômicas, desde que sempre sejam cumpridas normas essenciais como, por exemplo, a proibição de cortes rasos em área superior a 0,5 hectares ou, para florestas em regime de alto fuste equiâneo, o corte numa idade inferior a 60 anos. Também são desconhecidas fórmulas ou mesmo a fixação de números ou fatores semelhantes às regulamentações existentes no Código Florestal Estadual do Rio Grande do Sul. Em caso de dúvida, quem decide é o técnico do Serviço Florestal com base na situação específica do local.

Para organizar os trabalhos florestais nas pequenas propriedades existem os chamados "planos de trabalho". Para sua definição, o agricultor pode frequentar cursos oferecidos pelos centros de capacitação do Serviço de Extensão Florestal, nos quais aprende a fazer as atividades técnicas. Estes planos de trabalho ajudam a estruturar a floresta em unidades de trabalho, para as quais se determinam as intervenções necessárias nos próximos períodos, conforme critérios silviculturais, fixando uma ordem de prioridades para sua realização, bem como estimando, de forma grosseira, o montante de madeira a ser obtida pelos cortes planejados. Por regra, não existe um inventário florestal por propriedade, devido ao alto custo, podendo ocorrer o inventário florestal expedito abrangendo as florestas das propriedades que compõem uma Comunidade de Manejo Florestal (CMF). Neste tipo de inventário analisa-se a soma dos povoamentos dos proprietários associados, mas não se pode dar informação pormenorizada, individual ao sócio.

Para microrregiões, que incluem a extensão de alguns municípios, existem informações fornecidas pelo inventário florestal nacional, com valores médios de estoques, incrementos e de outras características que fornecem uma orientação geral, mas pouco úteis para definir tratamentos indicados às necessidades de um sítio ou povoamento específico. Deve-se considerar que, na maioria das vezes, trata-se de regiões coloniais, povoadas e trabalhadas há muitos séculos onde não existem mais florestas virgens, mas influenciadas, utilizadas e manejadas e, por isto, modificadas.

A vegetação florestal nativa é dominada por uma série de espécies valiosas entre latifoliadas nas

Ci. Fl., v. 28, n. 3, jul. - set., 2018 
menores altitudes e coníferas nas encostas e montanhas, assemelhando-se um pouco à presença da araucária no relevo do Rio Grande do Sul.

Nesse ambiente topograficamente muito estruturado, onde transcorreu a alteração milenar dos ecossistemas e dos sítios pela ação do homem, não é possível orientar o manejo por uma suposta vegetação primária. Então, a tarefa atual consiste no aproveitamento das condições encontradas na floresta, em geral de povoamentos heterogêneos e, preferencialmente originados de regeneração natural, formando mosaicos com reflorestamentos.

Até há pouco tempo, na seleção das espécies, dava-se preferência às coníferas nativas, e pouca atenção às latifoliadas. Esta situação mudou, principalmente por orientação do mercado. Isto porque, a produção de sortimentos nobres de latifoliadas encontrou melhores preços e, por outro lado, pela procura crescente de madeira para energia, levando a uma expressiva valorização de preços nos dois segmentos.

Paralelamente, o apelo ecológico mostrou que as florestas mistas são mais estáveis e menos sujeitas a danos climáticos (ventanias, nevascas), que muitas vezes são seguidos por danos bióticos (insetos). Assim, os inventários nacionais provam que a composição das florestas austríacas, há décadas, está mudando cada vez mais para floresta mista e inequiânea.

Em resumo, constata-se que as florestas latifoliadas vêm recebendo mais atenção e a meta não é mais a produção de grandes quantidades de sortimentos industriais ou de lenha, mas a melhoria qualitativa, passando a quantidade para segundo plano. Assim, a parte inferior do tronco está no centro da atenção do manejo, e passa a ser o suporte econômico, enquanto as demais partes serão de uso secundário, destinadas à indústria ou energia.

$\mathrm{Na}$ busca de uma silvicultura mais próxima da natureza é fácil constatar o maior cuidado na relação entre o sítio e a espécie. Os ciclos longos de produção não possibilitam uma eventual mudança da composição das espécies em curto prazo. Optar pela renovação natural, quando possível, pode ser uma boa escolha, pois além de ser mais barata do que o plantio artificial, permite a formação de um mosaico de espécies e densidades distribuídas segundo a capacidade de suporte do sítio.

Neste sentido, atualmente vem sendo executado um projeto de cooperação entre instituições de pesquisa e de extensão para realizar um mapeamento ecológico detalhado, com o objetivo de orientar o agricultor, em nível de sítio, sobre a aptidão das espécies no sentido ecológico, econômico e de minimização de riscos.

Em florestas heterogêneas, a orientação do manejo precisa ser essencialmente silvicultural, muitas vezes voltada ao indivíduo ou grupos de árvores. Nestas condições florestais, as tabelas de produção não podem ser aplicadas. Para exemplificar, considerando-se o critério de qualificação e dimensionamento, hoje recomendado para a produção de madeira de qualidade. Sob esse aspecto, as árvores de espécies nobres e de qualidade superior devem alcançar um diâmetro acima de 50 a $60 \mathrm{~cm}$, com tronco livre de nós e de danos. Sob essas condições, o preço por metro cúbico pode ser várias vezes maior que o da madeira industrial.

Em geral, a presença desses exemplares em uma floresta sem manejo constante é bastante rara. Com a aplicação de tratamentos silviculturais, a frequência aumenta sensivelmente e, com isto, a rentabilidade econômica, remunerando efetivamente o trabalho intensivo e autônomo do pequeno proprietário.

No manejo dispensa-se a descrição do estabelecimento da regeneração natural; pensa-se na situação da parcela, no grupo de espécies ou no pequeno povoamento, a partir do ponto em que as árvores alcançam de 1 a $2 \mathrm{~m}$ de altura, sempre centralizando as atividades nas espécies desejadas. Neste sistema é essencial que ocorra uma densidade elevada de plantas no estágio jovem, para que a competição lateral iniba o engrossamento da ramificação e inicie, desde cedo, a desrama natural. Quando isto não ocorre, as podas moderadas podem ajudar o processo.

Para obter um povoamento misto em longo prazo é preciso que, neste estágio inicial e denso, não ocorra uma mistura individual de espécies, mas sim, um mosaico de grupos homogêneos, pois só assim será garantida a sobrevivência de, pelo menos, um representante do grupo. Este período de crescimento, com espaço reduzido, é chamado de período de qualificação, o qual dura até a árvore apresentar um tronco limpo, de comprimento variando entre $1 / 4$ a $1 / 3$ da altura que a árvores alcançará na idade de corte. Desta forma, apresentará potencialmente, uma tora de 5 a $8 \mathrm{~m}$ que, no futuro, equivale a mais de $80 \%$ do valor total da árvore.

Durante o período de qualificação é preciso também acompanhar o desenvolvimento das copas 
para evitar o seu atrofiamento. Somente uma copa vital é capaz de proporcionar crescimento e satisfazer o dimensionamento que ocorrerá no período seguinte. Dependendo do comportamento biométrico e das propriedades da madeira da espécie considerada seguem-se, periodicamente, cortes de liberação da árvore para que possa alcançar um bom incremento diamétrico. Desta maneira, as árvores devem ganhar diâmetro, alcançando a dimensão desejada mais cedo.

No manejo de alto fuste tradicional, as árvores alcançam grandes diâmetros somente em idades avançadas, nas quais os processos de degradação da madeira tornam-se mais frequentes. Ao acelerar o incremento em diâmetro consegue-se contornar o aparecimento de defeitos que desvalorizam a madeira, como por exemplo, as feridas deixadas pela poda dos galhos grossos, secos e apodrecidos que permitem a entrada de substâncias que oxidam o cerne.

Uma vez iniciada a fase de dimensionamento deve ser dada atenção especial à vitalidade das partes inferiores da copa.

Considerando a dimensão desejada para a árvore, deve-se considerar que uma copa excessivamente grande implica na redução do número de árvores potenciais na área, pois, no máximo, 50 a 100 árvores de elevada qualidade poderiam crescer por hectare. Nesta condição, sobra espaço generoso para as árvores de outras espécies crescerem intercaladas, que alcançam dimensões menores e permitem estruturar o sistema.

O procedimento descrito requer a existência de regeneração natural adequada. Caso hajam áreas sem a devida renovação, deve-se optar por um enriquecimento em grupos esparsos, cada um composto de 10 ou mais plantas de uma mesma espécie, plantadas em espaçamentos reduzidos.

Para o desenvolvimento de manejo tão intensivo, que inclui a exploração de árvores individuais ou de cortes em pequena extensão, é necessário existir acessibilidade adequada aos povoamentos e equipamentos adaptados às operações em pequena escala.

Para a infraestrutura de exploração é ideal a combinação de estradas que dão passagem a caminhões e de caminhos simples. Os equipamentos e acessórios usados devem ser de fácil montagem nos tratores usados no trabalho agrícola. Existem também incentivos para aquisição e uso de máquinas e equipamentos, os quais, muitas vezes, são de uso comunitário.

\section{A UTILIZAÇÃO DAS FLORESTAS NATIVAS: "UMA BELA ADORMECIDA"}

$\mathrm{Na}$ Áustria foi considerado essencial desenvolver uma política adequada para o setor de florestas produtivas em pequenas propriedades para que o ambiente rural tivesse futuro.

A combinação entre condições topográficas difíceis, elevada participação de coberturas florestais e uma estrutura fundiária dominada por propriedades familiares dificultava a sobrevivência econômica com base tão somente na agricultura e na pecuária. Nessas condições, a madeira oferecia-se como uma opção lógica para a geração alternativa de rendas.

Uma pesquisa entre agricultores com até 20 hectares de floresta revelou que os mesmos extraiam entre 5 a $50 \%$ da renda total da propriedade com a venda de madeira industrial e de lenha. Porém, para obter uma parcela razoável da renda da propriedade, não era suficiente que o agricultor soubesse manejar somente a motosserra, mas precisava ter experiência quanto às exigências ecológicas das espécies, obedecer às normas de elaboração dos sortimentos, bem como conhecer as técnicas de cortes e de extração.

Para obter tal conhecimento, caso deseje, pode receber assistência técnica. O Serviço de Extensão incentiva os proprietários organizando excursões, palestras e cursos. Em apoio à política florestal, o Ministério de Agricultura e Florestas prestigia anualmente 10 propriedades com o "Premio Nacional por Manejo Florestal Exemplar". Tal iniciativa busca despertar ainda mais o interesse pelo trabalho nas florestas e melhorar o estado e a capacidade produtiva das mesmas, o que beneficia não somente o agricultor, mas também a indústria de transformação, o mercado de trabalho e a balança comercial do país. Isto porque, na Áustria, o turismo e os produtos de madeira são os dois setores que mais se destacam na geração de divisas.

Até a pouco tempo, a produção de madeira em pequena escala parecia não ter condições de competir no mercado globalizado (SAYER, 2001). Os efeitos dos aumentos recentes nos custos de transporte fizeram com que se incentivasse a produção para distâncias curtas. A produção de sortimentos de maior qualidade foi uma reação lógica para atender aos mercados mais distantes e o crescimento exponencial dos mercados regionais de energia renovável abriu uma oportunidade para a comercialização de sortimentos de baixo 
valor, sem maiores custos de transportes.

A situação do uso das florestas nas pequenas propriedades, hoje é bem mais promissora do que na época de energia barata. Esta vem contribuindo significativamente, porque não há obstáculos administrativos ou a necessidade de técnicas especiais para o manejo, o qual se concentra em apreciável número de espécies. Não existe incompatibilidade entre um manejo de florestas nativas, a manutenção e a satisfação da demanda de produtos imateriais

O Rio Grande do Sul, na sua condição primária, tinha uma cobertura florestal em menos da metade de sua extensão territorial. Ainda hoje é consenso, que ele é um estado com um perfil florestal nítido, seja pelos reflorestamentos existentes ou em vias de implantação, seja pelas florestas nativas em fase de recuperação, sobretudo na formação florestal com araucária, que apresenta um excelente valor tecnológico e ecológico.

A transferência de experiências internacionais foi bastante útil para a realização das primeiras plantações industriais de exóticas no Brasil. Atualmente, o país é capaz de exportar experiências e tecnologias geradas localmente. Assim, poder-se-ia questionar, por que as experiências de outros países, com a utilização consciente de florestas nativas, não poderiam ter serventia? Não como modelo, mas de incentivo para a reflexão sobre as matas nativas do Rio Grande do Sul, que se encontram em uma posição de morte aparente, igual a uma Bela Adormecida, esperando ser despertada para que sua potencialidade resolva vários desafios simultaneamente. Neste sentido, já houve uma reivindicação quanto à falta de políticas consistentes para desenvolver o segmento de florestas nativas (SOCIEDADE BRASILEIRA DE SILVICULTURA, 2006).

\section{CONSIDERAÇÕES FINAIS}

Do anteriormente exposto, pode-se inferir que o manejo das pequenas unidades florestais, quando baseado em uma legislação adequada, no trabalho do serviço de extensão e de pesquisa, gera um ambiente no qual os benefícios materiais e imateriais da floresta aliam-se aos interesses da sociedade e aos econômicos dos proprietários, permite alcançar um regime de sustentabilidade periódico, no qual as intervenções silviculturais devem ser direcionadas às condições locais da floresta, sendo o objetivo central a árvore e não o povoamento.

Finalmente, acrescenta-se que é necessário haver continuidade neste processo de reivindicação quanto à falta de políticas consistentes para o desenvolvimento do segmento de florestas nativas, para possibilitar o manejo de florestas nativas com o objetivo de produzir bens materiais e imateriais de maneira constante e contínua no tempo, em benefício dos proprietários e de toda a sociedade.

\section{REFERÊNCIAS}

GLÜCK, P. Der Beitrag der Forstwirtschaft zur Funktionsfähigkeit des ländlichen Raumes. In: WYTZRENS H. K. Funktionsfähigkeit des ländlichen Raumes. Wissenschaftsverlag: Vauk Kiel KG, 1999. p. 73-85. IBAMA. Glossário - Serviços. Brasília: IBAMA, 2010. Disponível em: <http://www. ibama.gov.br>. Acesso em 2010.

INSTITUTO DO HOMEM E MEIO AMBIENTE DA AMAZÔNIA. [Web site]. Belém: IMAZON, 2008. Disponível em: <http://www.imazon.org.br/>. Acesso em 19 de Novembro de 2008.

LEBENSMINISTERIUM. Grüner Bericht. Viena: [s.n.], 2008. Disponível em: <http://www.grünerbericht/ at>. Acesso em 23. de Outubro de 2008.

LENTINI, M.; VERISSIMO, A.; PEREIRA, D. A expansão madeireira na Amazônia. O Estado da Amazônia. [s. 1. : s. n.], 2005. 4 p. Disponível em: <http://www.imazon.org.br>. Acesso em 19 de Novembro de 2008. 
NIEUWENHUYSE, A. et al. Can Forestry be a competitive land use option? Model simulation from humid tropical Costa Rica. Forest Ecology and Management, Amsterdam, v. 137, p. 23-40, 2000.

RIO GRANDE DO SUL. Secretaria Estadual do Meio Ambiente. [Web site]. Porto Alegre: SEMA, 2008. Disponível em: <http://www.sema.rs.gov.br>. Acesso em 2008.

SAYER, J. A. Tropical forests: diverging development paradigms. Unasylva, [s. 1.], v. 52, 2001.

SOCIEDADE BRASILEIRA DE SILVICULTURA. Fatos e números do Brasil florestal. [s. 1.: s. n.], 2006. 109 p. Disponível em: <http://www.sbs.org.br>. Acesso 22 de Dezembro de 2006.

SMERALDI, R.; VERISSMO, A. Acertando o alvo: o consumo de madeira no mercado interno brasileiro e promoção da certificação florestal. São Paulo: Amigos da Terra, 1999. 41 p. Disponível em: $<$ http://www. amazonia.org.br/meio2.htm>. Acesso em 16 de Novembro de 1999.

TOMASELLI, I. Forests and the future: regional perspective. Latin America and the Caribbean. Unasylva, [s. 1.], v. 52, n. 204, p. 44-46, 2001. 